\title{
Blood group does not appear to affect longevity a pilot study in centenarians from Western Sicily
}

\author{
Sonya Vasto $\cdot$ Calogero Caruso $\cdot$ \\ Laura Castiglia • Giovanni Duro • \\ Roberto Monastero • Claudia Rizzo
}

\begin{abstract}
Centenarians are the best example of extreme human longevity, and they represent a selected population in which the appearance of major age-related diseases, such as cancer, and cardiovascular diseases among others, has been consistently delayed or escaped. The study of the long-lived individual genetic profile has the purpose to possibly identify the genes and the allelic variations influencing extended life expectancy, hence considering them as biomarkers of age-related diseases onset and development. The present study shows no significant differences between allelic variations of $\mathrm{ABO}$ blood
\end{abstract}

S. Vasto · C. Caruso · L. Castiglia · C. Rizzo Immunohaemathology Unit, University Medical School "Paolo Giaccone" Hospital, Palermo, PA, Italy

S. Vasto · C. Caruso - L. Castiglia · C. Rizzo Department of Pathobiology, Medical and Forensic Biotechnologies, University of Palermo, Palermo, PA, Italy

R. Monastero

Department of Experimental Biomedicine and Clinical Neurosciences, University of Palermo, Palermo, PA, Italy

G. Duro

National Research Council, Palermo, PA, Italy

S. Vasto $(\bowtie)$

U.O. di Immunoematologia e Medicina Trasfusionale, AOUP PAOLO GIACCONE, Via Del Vespro 129, 90127 Palermo, PA, Italy

e-mail: s.vasto@unipa.it groups among a group of centenarians from Western Sicily.

Keywords $\mathrm{ABO} \cdot$ Centenarian · Genotyping · Immunogenetics · Longevity

\section{Introduction}

In order to understand one of the possible bases of longevity we have taken centenarians as a model. In Europe, centenarians account for 1/10000 inhabitants although there are some places where the ratio is lower like in some places of Ogliastra (Sardinia) and other places in the Monti Sicani (Sicily). These subjects represent a segment of the population surviving to extreme old age and age-related diseases such as cancer and cardiovascular diseases. We believe that learning from their experience is the best way to understand how they beat the odds of environmental and biological obstacles to which most humans fall prey (Capri et al. 2008; Franceschi et al. 2008).

Undeniably, the increase of the human life span is not simply due to the improved economic, cultural conditions and social/health cares, but also to the synergy among those and the genetic variability present in human populations. These factors are the target of a variety of studies, aimed to identify the 
genes and polymorphic variants, which could have a fundamental role in the attainment of extreme longevity in different countries characterized by different genetic pool, cultural habits and survival probability. Thus, the scenario of human longevity is getting more and more complex, as demographic conditions change and scientific knowledge increases raising new insights into this puzzling and sometimes contradicting topic (Capri et al. 2008; Franceschi et al. 2008; Candore et al. 2010a).

In this study we tried to attempt a possible connection between the histo-blood group $\mathrm{ABO}$ and life expectancy, ABO group is the major human alloantigen system which involves three carbohydrate antigens $(\mathrm{ABH})$ which has been studied by molecular biology applications, since 1990. Individuals who are $\mathrm{A}, \mathrm{B}$ and $\mathrm{AB}$ express glycosyltransferase activities converting the $\mathrm{H}$ antigen into $\mathrm{A}$ or $\mathrm{B}$ antigens, whereas $\mathrm{O}(\mathrm{H})$ individuals lack such activity. The gene encodes a glycosyltransferase, which moves $\mathrm{N}$-acetyl D-galactosamine (group A) or D-galactose (group B) to the nonreducing ends of glycans on glycoproteins and glycolipids. If a person shows neither A nor B transferase, he/she belongs to the group $\mathrm{O}$ while the expression of both transferases indicate $\mathrm{AB}$ group. The genes for the $\mathrm{A}$ and $\mathrm{B}$ transferase are located on the long arm of chromosome 9 (9q34). They consist of seven exons with a total length of 1065 base pairs. The most significant mutations are located on exons 6 and 7 that contain $77 \%$ of the full coding regions. There are 5 main alleles described in literature: A1, A2, B1, O1 and $\mathrm{O} 2$; there are many variations and subgroups (Daniels, 2009).

Historically, the ABO phenotype was one of the first marker to be typed both for studying disease (Aird et al. 1953, 1954) and ageing (Murray, 1961). In the present paper, we attempted to find any difference between allelic variations of $\mathrm{ABO}$ blood groups among a group of centenarians from Western Sicily and a population represented by healthy blood donors.

\section{Materials and methods}

We have genotyped 38 centenarians (15 males and 23 females, age range 100-107) and 59 healthy controls (44 males and 15 females, age range 45-65). The studied population came from Palermo surrounding municipalities in Western Sicily, Italy (Bürkle et al. 2007; Candore et al. 2010b). The age of Sicilian centenarians was verified by archival records at the municipal offices andlor church registries. We paid particular attention to the concordance between reported age and personal chronologies (age of marriage and of military service for men, age of first and last pregnancy for women, age of children, among others). This group did not have any cardiac risk factors or major age-related diseases (e.g., coronary heart disease, severe cognitive impairment, severe physical impairment, clinically evident cancer, or renal insufficiency), although some had decreased auditory and visual acuity, as would be expected. The healthy control group was recruited amongst healthy blood donors (from the same Palermo surrounding municipalities) who were judged to be in good health on the basis of their clinical history and blood tests (complete blood cell count, erythrocyte sedimentation rate, glucose, urea nitrogen, creatinine, electrolytes, C-reactive protein, liver function tests, iron, proteins, cholesterol, triglycerides). Since immigration and intermarriage have historically been rare, the Sicilian ethnicity of all participants was established if all four grandparents were born in Western Sicily. The study was approved by the University Hospital Ethics Committee, and written informed consent was obtained from all participants.

All samples were genotyped with BAGene ABOTYPE (Formedic, Mila, Italy). BAGene ready-to-use PCR-SSP kits allows the determination of the main alleles as well as the common subgroups. Allele frequencies were evaluated by gene count, and $2 \times 2$ tables were constructed to determine the statistical significance (chi-squared test with Yates correction) of differences in allele frequency for the $\mathrm{ABO}$ variants between centenarians and controls. The $P$ values obtained were multiplied for the number of alleles under study (Bonferroni correction). The data were tested for the goodness of fit between the observed and expected genotype values and their fit to Hardy-Weinberg Equilibrium (HWE).

\section{Results}

The aim of our study was to identify the allelic variations in the $\mathrm{ABO}$ group which could be 
Table 1 ABO Genotypic results in healthy people and centenarians

\begin{tabular}{|c|c|c|c|c|c|c|}
\hline \multirow[t]{2}{*}{ Alleles } & \multicolumn{3}{|c|}{ Controls $\mathrm{n}=59$} & \multicolumn{3}{|c|}{ Centenarians $\mathrm{n}=38$} \\
\hline & Total & Women & Men & Total & Women & Men \\
\hline$A^{1}$ & $18(30.5 \%)$ & $6(10.2 \%)$ & $12(20.3 \%)$ & $15(39.5 \%)$ & $9(23.7 \%)$ & $6(15.8 \%)$ \\
\hline$A^{1 v}$ & $1(1.7 \%)$ & $1(1.7 \%)$ & - & - & - & - \\
\hline$A^{x}$ & $1(1.7 \%)$ & $1(1.7 \%)$ & - & - & - & - \\
\hline$A^{2}$ & $2(3.4 \%)$ & $1(1.7 \%)$ & $1(1.7 \%)$ & $1(2.6 \%)$ & $1(2.6 \%)$ & - \\
\hline $\mathrm{B}^{1}$ & $11(18.6 \%)$ & $1(1.7 \%)$ & $10(16.9 \%)$ & $5(13 \%)$ & $2(5.2 \%)$ & $3(7.9 \%)$ \\
\hline$B^{3}$ & $1(1.7 \%)$ & - & $1(1.7 \%)$ & - & - & - \\
\hline $\mathrm{O}^{1}$ & $52(88.1 \%)$ & $13(22 \%)$ & $39(66.1 \%)$ & $32(84.2 \%)$ & $21(55.3 \%)$ & $11(28.9 \%)$ \\
\hline $\mathrm{O}^{1 \mathrm{v}}$ & $29(49.1 \%)$ & $5(8.5 \%)$ & $24(40.7 \%)$ & $20(52.6 \%)$ & $13(34.2 \%)$ & $7(18.4 \%)$ \\
\hline $\mathrm{O}^{2}$ & $2(3.4 \%)$ & $1(1.7 \%)$ & $1(1.7 \%)$ & $3(7.9 \%)$ & - & $3(7.9 \%)$ \\
\hline
\end{tabular}

No significant differences were observed comparing data of centenarians with those of controls

associated to a possible increase in life span. Table 1 shows the $\mathrm{ABO}$ alleles frequencies in 59 healthy controls and 38 centenarians. The frequencies of the genes under investigation were consistent with those predicted by the HWE. The results indicate that centenarians show a frequency of the A1 allele of around $39.5 \%$, higher than the value observed in controls $(30.5 \%)$ (Table 1).

This not significant increase has been compensated by a decrease in the other $\mathrm{ABO}$ allele frequencies, which were lower in comparison to those observed in controls (due to the small size of the samples data were not analysed according to the gender). In controls, the frequencies of major $\mathrm{ABO}$ alleles are not significantly different from those observed in the Sicilian healthy blood donors on the whole (The most common allele A1 shows a percentage of 30.5 in control population against 39.5 in centenarians. The percentage of $\mathrm{B} 1$ is 18.6 in control population against 13 in centenarians while the most common allele $\mathrm{O} 1$ shows a percentage of 88.1 in control population against 84.2 in centenarians).

\section{Discussion}

More than 65 years ago, it was postulated that individuals belonging to the different blood groups were not equally viable and it was suggested to study in any detail the blood group distributions in patients suffering from a wide variety of diseases (Ford 1945). Accordingly, several studies have shown significant association between $\mathrm{ABO}$ alleles and different types of disease although with contrasting results (Garratty, 2000; Anstee, 2010). Different problems like small sample sizes, the potential for population stratification, and modest statistical significance have headed to suspicion regarding the results. Nonetheless, some associations appear striking, including an increased risk of severe Plasmodium falciparum malaria in those with non-O alleles. (Fry et al. 2008; Anstee, 2010). Furthermore, numerous studies showed a strong association of non-O blood group with arterial and venous thromboembolism due to the presence, in A/B subjects, of high levels of von Willebrand Factor and Factor VIII (Anstee, 2010). There are other examples of infectious diseases in which the severity of infection can be directly linked to $\mathrm{ABO}$ phenotype. Patients of group $\mathrm{O}$ were more susceptible to severe infections by Vibrio cholerae than non-O patients (Harris et al. 2005) and in an outbreak of gastrointestinal infections caused by Escherichia coli $\mathrm{O} 157$ in Scotland in 1996, $87.5 \%$ of patients who died were group O (Blackwell et al. 2002).

On the other hand, in a prospective study performed on Scandinavian blood donors, it was clearly established that blood group A was associated with a higher risk of cancer of stomach, whereas blood group B was associated with peptic ulcers (Edgren et al. 2010). A possible explanations might be linked to different susceptibilities and immunologic responses to $H$. pylory.

Without any doubt, human longevity appears to be inextricably linked to optimal functioning of the immune system, suggesting that specific genetic determinants may reside in loci that regulate the 
immune response to infectious diseases (Candore et al. 2003). Additionally, in our previous work, concerning human leukocyte antigen (HLA) and killer cell immunoglobulin-like receptor (KIR), we suggested that the HLA/KIR/longevity associations are population specific, since these are heavily affected by the population-specific genetic and environmental history (Listì et al. 2010).

Concerning $\mathrm{ABO}$ blood group, there are only four reports suggesting a possible association between ABO blood groups and ageing/longevity features, among those only one performed on centenarians and none performed by molecular methods. In the first one, a significant increase of A blood type was observed in the healthy elderly male population over 64 years of age from UK (Murray, 1961). In a study carried out on a small sample of very longevous Turkish population, no association was found (Sturgeon et al. 1969); however, the validity of age claims was very questionable because birth certificates were not available. In a survey of 269 Japanese centenarians, B allele was shown to be associated with longevity (Shimizu et al. 2004). However, in another study involving patients and healthy people from North Carolina (USA), B allele was not a marker for longevity but rather a marker for earlier death (Brecher and Hay, 2011). So, it seems that the association between ABO group and longevity are influenced by population-specific genetic and environmental history as for HLA and KIR antigens.

Our pilot study shows a not-significant increase of A1 allele in Sicilian centenarians. It is interesting to note that levels of serum soluble E-selectin, inflammatory marker of several diseases, including cardiovascular ones, are higher in $\mathrm{O} / \mathrm{O}$ individuals, whereas a single nucleotide polymorphism in A1 allele is associated with low levels of these inflammatory markers (Paterson et al. 2009). Caruso's group has performed several studies showing that inflammatory gene variants, responsible for a low inflammatory response or a high anti-inflammatory response are associated with longevity, avoiding or delaying the onset of cardiovascular disease (Capri et al. 2008; Candore et al. 2010a,b). So, our results, that need to be confirmed in a larger sample of centenarians, are in line with previous statement, because the presence of A1 allele in centenarians might be linked to the lower levels serum soluble E-selectin of this blood group. Lastly, any gene-longevity study should be always analyzed after gender stratification, in the current study this has not been done because of the small sample size.

Acknowledgments This work was supported by grants from the Italian Ministry of Education, University and Research to CC. LC was PhD student at Pathobiology Course of Palermo University (directed by CC) and this paper was in partial fulfillment of the requirement for her $\mathrm{PhD}$.

\section{References}

Aird I, Bentall HH, Roberts JA (1953) A relationship between cancer of stomach and the ABO blood groups. Br Med J 1:799-801

Aird I, Bentall HH, Mehigan JA, Roberts JA (1954) The blood groups in relation to peptic ulceration and carcinoma of colon, rectum, breast, and bronchus; an association between the ABO groups and peptic ulceration. Br Med J 2:315-321

Anstee DJ (2010) The relationship between blood groups and disease. Blood 115:4635-4643

Blackwell CC, Dundas S, James VS, Mackenzie DA, Braun JM, Alkout AM, Todd WT, Elton RA, Weir DM (2002) Blood group and susceptibility to disease caused by Escherichia coli O157. J Infect Dis 185:393-396

Brecher ME, Hay SN (2011) ABO blood type and longevity. Am J Clin Pathol 135:96-98

Bürkle A, Caselli G, Franceschi C, Mariani E, Sansoni P, Santoni A, Vecchio G, Witkowski JM, Caruso C (2007) Pathophysiology of ageing, longevity and age related diseases. Immun Ageing 4:4

Candore G, Colonna-Romano G, Lio D, Caruso C (2003) Immunological and immunogenetic markers of successful and unsuccessful ageing. In: Pawelec G (ed) Advances in cell aging and gerontology basic biology and clinical impact of immunosenescence. Elsevier Science, Amsterdam

Candore G, Balistreri CR, Colonna-Romano G, Lio D, Listì F, Vasto S, Caruso C (2010a) Gender-related immuneinflammatory factors, age-related diseases, and longevity. Rejuvenation Res. 13:292-297

Candore G, Caruso C, Colonna-Romano G (2010b) Inflammation, genetic background and longevity. Biogerontology 11:565-573

Capri M, Salvioli S, Monti D, Caruso C, Candore G, Vasto S, Olivieri F, Marchegiani F, Sansoni P, Baggio G, Mari D, Passarino G, De Benedictis G, Franceschi C (2008) Human longevity within an evolutionary perspective: the peculiar paradigm of a post-reproductive genetics. Exp Gerontol 43:53-60

Daniels G (2009) The molecular genetics of blood group polymorphism. Hum Genet 126:729-742

Edgren G, Hjalgrim H, Rostgaard K, Norda R, Wikman A, Melbye M, Nyrén O (2010) Risk of gastric cancer and peptic ulcers in relation to $\mathrm{ABO}$ blood type: a cohort study. Am J Epidemiol 172:1280-1285

Ford EB (1945) Polymorphism. Biol Rev 20:73-88 
Franceschi C, Motta M, Malaguarnera M, Capri M, Vasto S, Candore G, Caruso C (2008) The extreme longevity: the state of art in Italy. Exp Gerontol 43:45-52

Fry AE, Griffiths MJ, Auburn S, Diakite M, Forton JT, Green A, Richardson A, Wilson J, Jallow M, Sisay-Joof F, Pinder M, Peshu N, Williams TN, Marsh K, Molyneux ME, Taylor TE, Rockett KA, Kwiatkowski DP (2008) Common variation in the $\mathrm{ABO}$ glycosyltransferase is associated with susceptibility to severe Plasmodium falciparum malaria. Hum Mol Genet 17:567-576

Garratty G (2000) Blood groups and disease: a historical perspective. Transfus Med Rev 14:291-301

Harris JB, Khan AI, LaRocque RC, Dorer DJ, Chowdhury F, Faruque AS, Sack DA, Ryan ET, Qadri F, Calderwood SB (2005) Blood group, immunity, and risk of infection with Vibrio cholerae in an area of endemicity. Infect Immun 73:7422-7427

Listì F, Caruso M, Incalcaterra E, Hoffmann E, Caimi G, Balistreri CR, Vasto S, Scafidi V, Caruso C, Candore G (2008) Pro-inflammatory gene variants in myocardial infarction and longevity: implications for pharmacogenomics. Curr Pharm Des 14:2678-2685
Listì F, Caruso C, Colonna-Romano G, Lio D, Nuzzo D, Candore G (2010) HLA and KIR frequencies in Sicilian Centenarians. Rejuvenation Res. 13:314-318

Murray S (1961) ABO groups and Rh genotypes in the elderly. Br Med J 2:1472-1474

Paterson AD, Lopes-Virella MF, Waggott D, Boright AP, Hosseini M S, Carte RE, Shen E, Mirea L, Bharaj B, Sun L, Bull SB (2009) Genome-wide association identifies the $\mathrm{ABO}$ blood group as a major locus associated with serum levels of soluble E-selectin. Arterioscler Thromb Vasc Biol 29:1958-1967

Shimizu K, Hirose N, Ebihara Y, Arai Y, Hamamatsu M, Nakazawa S, Masui Y, Inagaki H, Gondo Y, Fujimori J, Kanno Y, Konishi K, Kitagawa K (2004) Blood type B might imply longevity. Exp Gerontol 39:1563-1565

Sturgeon P, Beller S, Bates E (1969) Study of blood group factors in longevity. J Gerontol 24:90-94

Vasto S, Candore G, Balistreri CR, Caruso M, ColonnaRomano G, Grimaldi MP, Listi F, Nuzzo D, Lio D, Caruso C (2007) Inflammatory networks in ageing, agerelated diseases and longevity. Mech Ageing Dev 128:83-91 